\title{
REVIEW
}

\section{Imaging as a biomarker in drug discovery for Alzheimer's disease: is MRI a suitable technology?}

\author{
Emilio Merlo Pich ${ }^{1 \dagger}$, Andreas Jeromin ${ }^{2 *}{ }^{*}$, Giovanni B Frisoni ${ }^{3}$, Derek Hill ${ }^{4,5}$, Andrew Lockhart ${ }^{6}$, Mark E Schmidt ${ }^{7}$, \\ Martin R Turner ${ }^{8}$, Stefania Mondello ${ }^{9}$ and William Z Potter ${ }^{10}$
}

\begin{abstract}
This review provides perspectives on the utility of magnetic resonance imaging (MRI) as a neuroimaging approach in the development of novel treatments for Alzheimer's disease. These considerations were generated in a roundtable at a recent Wellcome Trust meeting that included experts from academia and industry. It was agreed that MRI, either structural or functional, could be used as a diagnostic, for assessing worsening of disease status, for monitoring vascular pathology, and for stratifying clinical trial populations. It was agreed also that MRI implementation is in its infancy, requiring more evidence of association with the disease states, test-retest data, better standardization across multiple clinical sites, and application in multimodal approaches which include other imaging technologies, such as positron emission tomography, electroencephalography, and magnetoencephalography.
\end{abstract}

\section{Introduction}

This article is the result of a roundtable held at the Wellcome Trust in the context of the meeting 'Biomarkers for Brain Disorders: Challenges and Opportunities' in February 2013. The focus was on the relevance of neuroimaging biomarkers in the development of novel treatment in Alzheimer's disease (AD), with a particular focus on magnetic resonance imaging (MRI). AD is the most common form of senile dementia associated with cognitive decline, regional brain hypometabolism/atrophia, $\beta$-amyloid plaque deposition, accumulation of phosphorylated taucontaining neurofilament tangles (NFTs), vascular pathology, and neuroinflammation, and the diagnostic criteria of $\mathrm{AD}$ were recently amended [1]. Based on the experience of current precompetitive consortia such as the Alzheimer Disease Neuroimaging Initiative (ADNI) [2], the Innovative Medicine Initiative Pharma-Cog [3], or the Dominant Inherited Alzheimer Network [4], the general consensus was that MRI has great potential for improving novel drug development but is not a mature biomarker yet. As for other biomarkers, the current applications of neuroimaging include assistance in (a) the diagnosis of

\footnotetext{
* Correspondence: andreasjeromin@gmail.com

${ }^{\dagger}$ Equal contributors

${ }^{2}$ Atlantic Biomarkers, LLC, 316 NW 28th Terrace, Gainesville, FL 32607, USA

Full list of author information is available at the end of the article
}

dementia, (b) the selection of subjects for enrollment in clinical trials or for stratification, (c) the tracking of disease progression, (d) providing evidence for target engagement for new therapeutic agents, and (e) providing evidence of disease-modifying effects (that is, normalization of a pathologic signal in association with clinical improvement (surrogate marker)). The MRI literature is partially supportive for the first three applications, whereas the database for the last two applications is still growing [5-7]. The present article should not be seen as an exhaustive review of neuroimaging in $\mathrm{AD}$ research (as shown in [8-10]) but as an introduction to the uneven status of advancement of MRI technology for drug development.

\section{A practical question}

Developing a new drug is an evidence-based exercise. Collecting evidence relevant for decision-making to support the development of a novel chemical entity (NCE) requires investment in methodologies that are reliable, valid, and clinically relevant. In other words, we should answer the question: is it worthwhile to include a neuroimaging assessment in a clinical trial for a novel treatment in AD? If the method has regulatory approval, the inclusion in a clinical trial is generally supported. If not, the quality of the scientific data, the simplicity in execution, the 
reliability in multi-center assessment, and a reasonable cost would drive the decision for including imaging endpoints. In this case, expectations about trial outcome should be adjusted since the imaging measurements may deliver exploratory data whose real value will be appreciated only when combined with data coming from other research groups, possibly organized within precompetitive consortia (for example, ADNI). Remarkably, only a limited number of imaging biomarkers are endorsed by regulatory agencies (Table 1). A series of methodological challenges are still facing the neuroimaging scientific community. The most important are (a) the interpretation of the biological meaning of the various neuroimaging measurements and their relationship with disease severity, (b) the test-retest reliability, and (c) the proper implementation into multi-center clinical trials. Hence, one of the main goals of the scientific community should be to provide answers to these questions and contribute to the regulatory approval of the neuroimaging methods.

\section{Neuroimaging in Alzheimer's disease: the legacy of positron emission tomography}

Different neuroimaging modalities are at different stages of maturity regarding implementation in $\mathrm{AD}$ research. For example, for more than two decades, molecular neuroimaging assessed with positron emission tomography (PET), aimed to investigate key neurochemical processes at work in $\mathrm{AD}$, has been used with a certain success to assist the diagnostic process in $\mathrm{AD}$ research $[9,10]$. PET with [35] ${ }^{18}$ Fluoro-2-deoxy-D-glucose (FDG) used to map the cerebral metabolic rate of glucose was the first imaging methodology to receive regulatory approval for the diagnostic evaluation of dementia $[10,36]$. The extent and severity of glucose hypometabolism have been reported to be predictive of conversion to $\mathrm{AD}$ in prodromal $\mathrm{AD}$ patients, and to correlate with cognitive impairment in prodromal and probable $\mathrm{AD}[11,12,36]$. However, for longitudinal use, careful control and standardization of acquisition are necessary. In fact, as a measure of brain activity, FDG PET is susceptible to biological variability due to normal aging, current state of arousal level, local inflammation, and other nonneuronal sources of metabolic changes, possibly resulting in misdiagnosis $[10,13,14]$.

PET-mediated visualization of the amyloid plaques in the brain was obtained by using amyloid- $\beta$-selective radioligands, at first with the Pittsburgh compound $\mathrm{B}$ (11C-PiB) and later with the ${ }^{18} \mathrm{~F}$-labeled tracers (for example, florbetapir, flutemetamol, and florbetaben) [16,37]. Since 2011, several of these tracers received regulatory approval to assist in the diagnosis of dementia (in particular, for ruling out AD in favor of other forms of dementia when the amyloid- $\beta$ signal was absent in the presence of cognitive impairment, in line with the revised Research Diagnostic Criteria for AD) [1]. However, since elevated amyloid load was described in up to $15 \%$ of non-demented subjects with age-adjusted normal cognitive profile, it is unclear whether this represents an early marker for individuals that will develop the disease soon or normal variations of a biological parameter with loose association with the disease [35]. More recently, the abundant NFT pathology, another hallmark of AD, has been targeted with the initial development of two novel PET ligands in clinical exploration: 18 F-T-807 and 11C-PBB-3 $[38,39]$. It is notable that both amyloid- $\beta$ peptides and phosphorylated tau levels can be measured biochemically in the cerebrospinal fluid and are validated biomarkers in $\mathrm{AD}$ research [40], questioning the need for the more expensive neuroimaging.

Amyloid- $\beta$ PET recently qualified for the European regulatory agency (European Medicines Agency, or EMA) as a biomarker for population enrichment of clinical trials with prodromal and mild-moderate AD subjects (EMA/ CHMP/SAWP/893622/2011 and EMA/CHMP/SAWP/ 892998/2011). Amyloid- $\beta$-selective radioligands were also used to provide evidence of target engagement for NCE aimed at amyloid- $\beta$ plaques (that is, bapineuzumab [19] and gantenerumab [15]). These studies showed a significant dose-dependent reduction of the amyloid- $\beta$ PET signal over a period of several months of treatment. However, data available from large clinical trials indicate that changes of amyloid- $\beta$ signal were not associated with changes of disease clinical severity in patients with AD $[19,41]$ and, to date, should not be used as a surrogate marker for efficacy. A final note: the implementation of PET requires exposure to radioactivity that limits the repeated use in the same individuals as well as specialized centers and significant investment. Therefore, while PET can provide unique and useful information, these limitations challenge use in large clinical trials and even in community-based health care. In fact, for these reasons, PET is often implemented in a substudy of a larger multi-center clinical trial, targeting a sub-population of the whole study.

\section{Magnetic resonance imaging implementation in Alzheimer's disease research}

MRI-related techniques are gaining increasing interest since their use does not require radioactivity exposure and they can be easily repeated in the same subjects with no harm, are relatively inexpensive, and can be operated with scanner machines available in almost any hospital $[6,9,10]$. In clinical trials, MRI is commonly used as a radiologic diagnostic aid to exclude individuals with incidental brain pathologies. The evidence supporting their use as specific biomarkers for AD is still limited (Table 1). We briefly describe the most promising use of MRI. 
Table 1 Evidentiary table showing different imaging modalities implemented in AD research with relevant information

\begin{tabular}{|c|c|c|c|c|c|c|}
\hline & $\begin{array}{l}\text { Patient } \\
\text { population }\end{array}$ & $\begin{array}{l}\text { Current use. } \\
\text { (Potential clinical use) }\end{array}$ & $\begin{array}{l}\text { Cost; feasibility. } \\
\text { Burden }\end{array}$ & $\begin{array}{l}\text { Biological and } \\
\text { multi-center validation }\end{array}$ & Limitation & $\begin{array}{l}\text { Regulatory } \\
\text { status }\end{array}$ \\
\hline FDG PET & $\begin{array}{l}\mathrm{MCl}, \mathrm{AD}, \\
\text { and other } \\
\text { dementias }\end{array}$ & $\begin{array}{l}\text { Diagnostic; } \\
\text { stratification [10]; } \\
\text { provide support to } \\
\text { therapeutic clinic } \\
\text { effects [11]. (Disease } \\
\text { progression.) }\end{array}$ & $\begin{array}{l}\text { High cost; } \\
\text { - Feasible. } \\
\text { - IV infusion } \\
\text { radioactive } \\
\text { agent needed. }\end{array}$ & $\begin{array}{l}\text { Biological post-mortem } \\
\text { data. Guidelines for } \\
\text { single- and multi-site use, } \\
\text { vendor-specific protocols. } \\
\text { Standardized for multi- } \\
\text { center trials. High } \\
\text { validity [12]. }\end{array}$ & $\begin{array}{l}\text { Signal affected by } \\
\text { inflammation and } \\
\text { ischemia or behavior } \\
\text { state }[9,13] \text {; } \\
\text { misdiagnosis reported } \\
{[14] .}\end{array}$ & $\begin{array}{l}\text { Indicated for differential } \\
\text { diagnosis of dementia } \\
\text { (FDA and EMA) in } 2004 . \\
\text { No regulatory } \\
\text { qualification for use in } \\
\text { early AD at this time. }\end{array}$ \\
\hline $\begin{array}{l}\text { Amyloid- } \beta \\
\text { PET }\end{array}$ & $\begin{array}{l}\mathrm{MCl}, \mathrm{AD}, \\
\text { and other } \\
\text { dementias }\end{array}$ & $\begin{array}{l}\text { Diagnostic: AD } \\
\text { exclusion; stratification; } \\
\text { target engagement [15]. }\end{array}$ & $\begin{array}{l}\text { High cost; } \\
\text { - Difficult. } \\
\text { - IV infusion } \\
\text { radioactive } \\
\text { agent needed. }\end{array}$ & $\begin{array}{l}\text { Biological post-mortem } \\
\text { data [16]. Guidelines for } \\
\text { single- and multi-site use, } \\
\text { vendor-specific protocols. } \\
\text { Standardization for multi- } \\
\text { center trials partially } \\
\text { achieved [12]. }\end{array}$ & $\begin{array}{l}\text { Cases of normal } \\
\text { subjects with high } \\
\text { amyloid- } \beta \text { and cases } \\
\text { of subjects with } \\
\text { dementia with low } \\
\text { amyloid- } \beta \text {. Detection } \\
\text { threshold to be } \\
\text { validated [8]. }\end{array}$ & $\begin{array}{l}\text { Indicated for differential } \\
\text { diagnosis of dementia in } \\
2012 \text { (FDA and EMA). } \\
\text { Qualified as baseline } \\
\text { measure for selecting } \\
\text { patients for trials in } \\
\text { pre-dementia and } \\
\text { mild-moderate AD } \\
\text { (EMA). Regulatory guidance } \\
\text { for use in research and } \\
\text { drug development. }\end{array}$ \\
\hline $\begin{array}{l}\text { Volumetric } \\
\text { MRI }\end{array}$ & $\mathrm{MCl}, \mathrm{AD}$ & $\begin{array}{l}\text { Diagnostic [10]; } \\
\text { stratification using } \\
\text { hippocampal volume } \\
\text { [17,18]. (Disease } \\
\text { progression; provide } \\
\text { support to therapeutic } \\
\text { clinic effects.) }\end{array}$ & $\begin{array}{l}\text { Low cost; } \\
\text { - Easy. } \\
\text { Burden: no } \\
\text { pacemaker } \\
\text { carriers; claustro- } \\
\text { phobic reaction. }\end{array}$ & $\begin{array}{l}\text { SOPs for single and } \\
\text { multi-site; vendor- } \\
\text { specific protocols. } \\
\text { Standardization for } \\
\text { multi-center trials } \\
\text { partially achieved }[6,9] \text {. }\end{array}$ & $\begin{array}{l}\text { Lack molecular } \\
\text { specificity. Direct data } \\
\text { on hippocampal } \\
\text { histopathology. Loss of } \\
\text { volume as non-specific } \\
\text { atrophy [9]. Patterns } \\
\text { overlap with non-AD } \\
\text { disease or in advanced } \\
\text { aging. }\end{array}$ & $\begin{array}{l}\text { Hippocampal volume } \\
\text { qualified as baseline } \\
\text { measure for selecting } \\
\text { patients for trials in } \\
\text { pre-dementia AD/MCl } \\
\text { through EMA. Hippocampal } \\
\text { volume qualification for } \\
\text { patient stratification in } \\
\text { MCl/AD through CAMD/ } \\
\text { FDA in progress. }\end{array}$ \\
\hline ARIA MRI & $M C l, A D$ & $\begin{array}{l}\text { Safety signal; vascular } \\
\text { integrity; inflammation } \\
\text { [14]. }\end{array}$ & $\begin{array}{l}\text { Low cost; } \\
\text { - Easy. } \\
\text { Burden: no } \\
\text { pacemaker car- } \\
\text { riers; claustro- } \\
\text { phobic reaction. }\end{array}$ & $\begin{array}{l}\text { SOPs for single and } \\
\text { multi-site; vendor-specific } \\
\text { protocols. } \\
\text { Standardization for multi- } \\
\text { center trials achieved } \\
\text { [19]. }\end{array}$ & $\begin{array}{l}\text { Occurrence of } \\
\text { spontaneous ARIA in } \\
\text { elderly unknown. False } \\
\text { positive in untreated } \\
\text { APP duplication case. }\end{array}$ & $\begin{array}{l}\text { Requirement of } \\
\text { monitoring (several MRI } \\
\text { scans) during trials with } \\
\text { amyloid- } \beta \text {-lowering } \\
\text { agents (FDA and EMA). }\end{array}$ \\
\hline $\begin{array}{l}\text { DTI tracto- } \\
\text { graphy }\end{array}$ & $\begin{array}{l}\mathrm{MCl}, \mathrm{AD} \text {, } \\
\text { non-clinical } \\
\text { at genetic } \\
\text { risk subject }\end{array}$ & $\begin{array}{l}\text { Diagnostic [20]; } \\
\text { stratification; disease } \\
\text { progression. (Provide } \\
\text { support to therapeutic } \\
\text { clinic effects.) }\end{array}$ & $\begin{array}{l}\text { Low cost; } \\
\text { - Easy. } \\
\text { Burden: no } \\
\text { pacemaker } \\
\text { carriers; claustro- } \\
\text { phobic reaction. }\end{array}$ & $\begin{array}{l}\text { Biological validation in } \\
\text { progress [21]. SOPs for } \\
\text { single and multi-site; } \\
\text { vendor-specific test } \\
\text { protocols; standardization } \\
\text { for multi-center trials in } \\
\text { progress }[22,23] \text {. }\end{array}$ & $\begin{array}{l}\text { Head motion artifacts; } \\
\text { partial volume effects. } \\
\text { Limited direct data on } \\
\text { histopathology. Few } \\
\text { multimodal } \\
\text { relationships } \\
\text { established. }\end{array}$ & No regulatory guidelines \\
\hline $\begin{array}{l}\text { Resting- } \\
\text { state fMRI }\end{array}$ & $\begin{array}{l}\mathrm{MCl}, \mathrm{AD} \text {, } \\
\text { non-clinical } \\
\text { at genetic } \\
\text { risk subject }\end{array}$ & $\begin{array}{l}\text { (Provide support to } \\
\text { therapeutic clinic effect } \\
{[24,25] \text {. Stratification }} \\
{[26] ; \text { disease }} \\
\text { progression [7].) }\end{array}$ & $\begin{array}{l}\text { Low cost; } \\
\text { - Easy. } \\
\text { Burden: no } \\
\text { pacemaker } \\
\text { carriers; claustro- } \\
\text { phobic reaction. }\end{array}$ & $\begin{array}{l}\text { Various SOPs for BOLD } \\
\text { in single- }[27] \text { and multi- } \\
\text { center; ASL in single } \\
\text { center }[20,28] \text {. Test-retest } \\
\text { done }[7,29] \text {. } \\
\text { Standardization for } \\
\text { multi-center trials in } \\
\text { progress }[26] .\end{array}$ & $\begin{array}{l}\text { Head motion artifacts; } \\
\text { unclear biology; few } \\
\text { data in histopathology. } \\
\text { Preliminary data } \\
\text { longitudinal and } \\
\text { multimodal data } \\
\text { available [7]. }\end{array}$ & No regulatory guidelines \\
\hline $\begin{array}{l}\text { Memory } \\
\text { task - fMRI }\end{array}$ & $\begin{array}{l}\mathrm{MCl}, \mathrm{AD} \text {, } \\
\text { non-clinical } \\
\text { at genetic } \\
\text { risk subject }\end{array}$ & $\begin{array}{l}\text { (Provide support to } \\
\text { therapeutic clinic } \\
\text { effect. Stratification } \\
\text { [24]; disease } \\
\text { progression [30].) }\end{array}$ & $\begin{array}{l}\text { Middle cost; } \\
\text { - Complex. } \\
\text { Burden: no } \\
\text { pacemaker; } \\
\text { claustrophobic } \\
\text { reaction. }\end{array}$ & $\begin{array}{l}\text { Various SOPs for single } \\
\text { center [31,32]. Vendor- } \\
\text { specific test protocols. } \\
\text { No standard for } \\
\text { multi-center trials. } \\
\text { Test-retest not always } \\
\text { available [33]. }\end{array}$ & $\begin{array}{l}\text { Head motion artifacts; } \\
\text { difficult implementation } \\
\text { in cognitively impaired } \\
\text { subject Longitudinal } \\
\text { data available in part; } \\
\text { incomplete reliability } \\
\text { data }[9,34] .\end{array}$ & No regulatory guidelines \\
\hline
\end{tabular}

AD, Alzheimer's disease; APP, amyloid precursor protein; ARIA, amyloid-related imaging abnormality; ASL, arterial spin labeling; BOLD, brain oxygen leveldependent; CAMD, coalition against major diseases; DTI, diffusion tensor imaging; EMA, European Medicines Agency; FDA, US Food and Drug Administration; FDG, fluoro-2-deoxy-D-glucose; fMRI, functional magnetic resonance imaging; IV, intravenous; $\mathrm{MCl}$, mild cognitive impairment; MRI, magnetic resonance imaging; PET, positron emission tomography; SOP, standard operating procedure. 


\section{Structural magnetic resonance imaging}

Structural MRI is an imaging modality that describes the shape, size, and integrity of gray and white matter structures in the brain; it is highly sensitive to the atrophic and vascular changes that occur in the AD central nervous system [6].

\section{Volumetric magnetic resonance imaging}

Volumetric MRI is based on data collected by using T1weighted sequences that are quantified by using both manual and automatic image analysis. Whereas harmonization of manually segmented hippocampus is in progress [17], automated image analysis software (NeuroQuant; CorTechs Labs Inc., San Diego, CA, USA) was recently approved as a medical device to provide an aid in dementia diagnosis [18].

Volumetric MRI collected longitudinally at two or more time points is the most mature imaging biomarker of disease progression in $\mathrm{AD}$ [6], recently supported by multimodal evidence using FDG [36]. Progression of atrophy in the whole brain and in areas targeted by $A D$ (medial temporal lobe, temporoparietal, and restrosplenial cortex) represents a reliable marker of the neurodegenerative process underlying clinical symptoms, more robust than amyloidosis alone. Hippocampal volumetric MRI has been validated versus pathologic post-mortem markers such as neuronal loss and Braak stages [42]. Hippocampal volumetric MRI is qualified by EMA as a biomarker for enrichment of pre-dementia $\mathrm{AD}$ trials [17], these prodromal subjects having already lost about $20 \%$ of its volume. Progression of whole-brain and hippocampal atrophy has been shown to correlate closely with clinical worsening in patients with AD [6].

Notably, an unexpected paradoxical finding was reported in anti-amyloid immunotherapeutic studies in AD $[19,43]$, showing a reduced volume in hippocampus, whole brain, and cortex. These results are calling for a re-evaluation of the neurobiological interpretation of the volumetric MRI reduction. The short-term reduction of brain volume has been hypothesized to result from changes in fluid balance or amyloid plaque removal rather than a sustained increase in rate of atrophy. Multimodal studies including FDG PET and functional MRI (fMRI) as well as post-mortem studies would eventually lead to a better understanding of the biological underpinning of this phenomenon.

Methodologically, accurate volumetric assessment requires standard operating procedures that include the know-how specific for the modality, acquisition parameters, and suitable training of the staff [5]. For this reason, strict standardization of acquisition and measurement is being undertaken for manual hippocampal volumetry by a European Alzheimer's Disease Consortium (EADC)ADNI consortium under the auspices of the Alzheimer's
Association [17,44]. The EADC-ADNI standard operating procedures will be used to validate automated algorithms, such as FreeSurfer and Learning Embeddings Atlas Propagation. Other brain regions are under active investigation; for example, the entorhinal cortex showed performance similar to hippocampus using the Quarc analysis software (Quarc, Wedemark, Germany) [45]. According to this study, when these markers were used as primary endpoints, a sample size of about 100 subjects with $\mathrm{AD}$ would be sufficient to detect a $25 \%$ reduction of annual atrophy rate produced by a putative novel treatment [45]. This is at least threefold less than the sample size needed when using clinical scales such as the Alzheimer's Disease Assessment Scale-cognitive subscale as endpoints.

\section{Vascular magnetic resonance imaging}

The modality of T2-weighted/fluid inversion recovery is particularly useful to identify vasogenic edema and microhemorrhages, defined as the amyloid-related imaging abnormalities (ARIAs) in AD research [19,43]. Regulatory authorities require their use in clinical trials implementing the $\beta$-amyloid-lowering drugs for safety reasons. For example, in two bapimezumab phase II trials, ARIAs occurred in $17 \%$ of patients with $\mathrm{AD}, 78 \%$ of whom did not report clinical correlates [19]. The occurrence of ARIAs seems to depend on the dose of the $\beta$-amyloid-lowering drug and on the presence of the apolipoprotein $\mathrm{E} 4 \varepsilon$ genotype, which is characterized by a significantly higher $\beta$-amyloid burden [19,41]. A rating scale was recently proposed [46].

\section{Diffusion tensor imaging magnetic resonance imaging}

Through the assessment of the random motion of water molecules in the tissue, diffusion tensor imaging (DTI) has provided new tools to the study of white matter alterations in $\mathrm{AD}$ brain mostly by assessing two parameters: the fractal anisotropy (FA) and the mean diffusivity (MD). FA is considered a marker of axonal integrity and myelinization, whereas MD represents the overall cellular integrity [47]. The combined use of DTI and volumetric MRI in the cingulated cortex was shown to increase the imaging-based classification of $\mathrm{AD}$ cases versus control with up to $91 \%$ accuracy [21]. Initially, DTI has been perceived as a technique with poor reproducibility and site/scanner dependency. Recent multicenter trials in Huntington's disease and AD seem to contradict this preoccupation, suggesting a low centerdependent bias and a real possible use as a surrogate endpoint $[22,23]$.

\section{Functional magnetic resonance imaging}

fMRI can be defined as a technology that provides statistical maps of brain activation [6,7]. Brain activation is 
indirectly obtained by measuring changes of regional microcirculation produced by local neural activity triggered by external stimuli, behavioral performance, or neuroactive drugs. Two kinds of magnetic resonance signals are generally measured: the blood oxygenation level-dependent (BOLD) and the arterial spin labeling (ASL) signals $[7,48]$.

\section{Activation task functional magnetic resonance imaging procedures}

Most brain activation maps obtained in patients with $\mathrm{AD}$ have been generated during memory tasks and using BOLD, showing reduced activity in hippocampus/medial temporal lobe and increased activity in prefrontal cortex while encoding new information [30,31]. Similar abnormalities, in particular decreases in the medial temporal lobe, were observed in subjects with prodromal $\mathrm{AD} / \mathrm{mild}$ cognitive impairment (MCI) [48]. Intriguingly, increases were described in the early phase of the disease [32] and in asymptomatic individuals with genetic risk for $\mathrm{AD}$ [24]. This hyper-activation was interpreted as a possible compensatory mechanism at work within the networks whose structures were impaired, a pathologic marker of impending neural failure [9]. Whereas data on longitudinal test-retest were provided in single-center studies [33], fMRI activation tasks were very rarely used in multi-center studies, highlighting the need for further validation and standardization.

Logistically, the typical fMRI activation task is quite complex, requiring audio/visual support for stimuli presentation (for example, goggles) and performance recording (for example, joysticks), expert personnel, calibration procedures for each tasks, and proven invariance to repeated exposure (often not studied), therefore making their implementation difficult in multi-center trials or in routine use as a diagnostic in the community.

\section{Task-free functional magnetic resonance imaging procedures}

More recently, resting-state fMRI (rs-fMRI) was introduced to collect signals while the subject is not performing any particular tasks [6,7]. This task-free approach is ideal in poorly collaborative subjects, such as severely demented patients, and does not require a specialized staff. rs-fMRI is based on the collection of time series of whole-brain MRI signal fluctuations (generally BOLD) measured in each brain voxel while the subject is at rest $[6,7]$. The similarity between time series in different brain areas can be assessed mathematically as correlation matrices, indicating functional connectivity [29]. Consistent patterns of connectivity at resting state were reported by several authors, evaluated in test-retest protocol, and related to specific electrophysiological signatures in topologically restricted brain areas, exemplified by the 'default mode' network (DMN) [34]. In $\mathrm{AD}$, impaired $\mathrm{DMN}$ has been reported, including longitudinal data that showed a correlation with clinical symptom worsening [6]. Interestingly, rs-fMRI studies in non-demented adults carrying a familial AD gene mutation showed hyper-connectivity in the dorsolateral prefrontal cortex and decreased connectivity in the precuneus [26,27]. rs-fMRI is also a stronger classifier than memory task-associated fMRI when used in nondemented adults carrying a familial AD mutation [27]. Interestingly, changes of connectivity in the DMN of subjects with $\mathrm{AD}$ were observed following chronic treatment with memantine [49] and donepezil [25].

\section{Arterial spin labeling}

In the last few years, ASL has attracted the attention of various research groups [7]. ASL MRI was validated versus perfusion PET showing convergent information about regional cerebral blood flow of diagnostic relevance, with higher resolution and no exposure to radioactive tracers [25,28]. Evidence of hypoperfusion in $\mathrm{AD}$ and prodromal $\mathrm{AD} / \mathrm{MCI}$ conditions was confirmed and extended to a series of other brain areas, and the initial evidence is that ASL may have properties of diagnostics and markers of disease severity [20,25,50]. ASL measurements appear less variable than BOLD in test-retest trials in a single center. Unfortunately, to date, it cannot be easily implemented in multi-center trials since different vendors of MRI scanners have implemented different sequences of acquisition, therefore hindering comparison among sites with different MRI scanners.

\section{Conclusions and future directions}

There is a role for MRI as a biomarker in clinical trials aimed at the development of new treatment for AD. However, a series of challenges is still looming, in particular for fMRI. Among them, we have identified reliability and repeatability for specific tests, standardization across multiple sites, development of validated automated quantification tools, implementation of multiple modalities (for example, merging PET and rs-fMRI), cost optimization, and selection of the most accurate and efficient diagnostic combination of markers, including fluid-based biomarker modalities. Most of these challenges are tackled in the context of large consortia involving collaborations between academia and industry as well as in some contract research organizations and technology-oriented academic centers. The delivery of this research is of relevance for building confidence in imaging biomarkers: at present, with the exception of safety assessment of ARIA signals, the implementation of MRI in pharmaceutical clinical trials is still seen as exploratory rather than decision-making. 


\section{Abbreviations}

AD: Alzheimer's disease; ADNI: Alzheimer Disease Neuroimaging Initiative; ARIA: Amyloid-related imaging abnormality; ASL: Arterial spin labeling; BOLD: Blood oxygen level-dependent; DMN: Default mode network; DTI: Diffusion tensor imaging; EADC: European Alzheimer's Disease Consortium; EMA: European Medicines Agency; FA: Fractal anisotropy; FDG: Fluoro-2-deoxy-D-glucose; fMRI: Functional magnetic resonance imaging; MCl: Mild cognitive impairment; MD: Mean diffusivity; MRI: Magnetic resonance imaging; NCE: Novel chemical entity; NFT: Neurofibrillary tangle; PET: Positron emission tomography; rs-fMRl: Resting-state functional magnetic resonance imaging.

\section{Competing interests}

$\mathrm{AL}$ is an employee of GlaxoSmithKline (Brentford, UK). MES is an employee of Janssen Pharmaceutica (Beerse, Belgium). AJ is an employee of Atlantic Biomarkers, LLC (Gainesville, FL, USA). EMP is an employee of F. Hoffmann-La Roche AG (Basel, Switzerland). DH is an employee of IXICO (London, UK). GBF has served on advisory boards for Eli Lilly and Company (Indianapolis, IN, USA), Bristol-Myers Squibb (New York, NY, USA), Bayer (Leverkusen, Germany), Lundbeck (Copenhagen, Denmark), Elan (Dublin, Ireland), AstraZeneca (London, UK), Pfizer Inc (New York, NY, USA), TauRx (Aberdeen, UK), Wyeth (Philadelphia, PA, USA), GE (Fairfield, CT, USA), and Baxter (Deerfield, IL, USA); is a member of the editorial boards of Lancet Neurology, Aging Clinical \& Experimental Research, Alzheimer's Diseases \& Associated Disorders, and Neurodegenerative Diseases; is the imaging section editor of Neurobiology of Aging; has received grants from Wyeth International, Lilly International, Lundbeck Italia, GE International, Avid/Lilly, Roche, and the Alzheimer's Association; and in the past 2 years has received lecture fees to speak at the invitation of Lundbeck. WZP has served on advisory boards for Amgen (Thousand Oaks, CA, USA), Allelix (Mississauga, ON, Canada), Ironwood (Cambridge, MA, USA), Eli Lilly and Company, Taisho (Tokyo, Japan), Takeda (Osaka, Japan), and Teva (Petah Tikva, Israel) in the last 12 months. SM declares that she has no competing interests.

\section{Acknowledgments}

We thank the participants of the Wellcome Trust meeting on Brain Disorders for discussion, the Wellcome Trust for support, and Treasan Creavin and Lucy Criddle for their help in organizing this venue.

\section{Author details}

${ }^{1}$ Clinical Imaging, Neuroscience DTA pRED, F. Hoffman-La Roche, Grenzacherstrasse $124 \mathrm{CH}-4070$, Basel, CH, Switzerland. ${ }^{2}$ Atlantic Biomarkers, LLC, 316 NW 28th Terrace, Gainesville, FL 32607, USA. ${ }^{3}$ IRCCS San Giovanni di Dio Fatebenefratelli, Laboratory of Epidemiology, Neuroimaging, and Telemedicine, via Pilastroni 4, Brescia 25125, Italy. ${ }^{4}$ Medical Imaging Science, UCL, London, UK. ${ }^{5} \mathrm{XICO}$ Ltd, Floor 4, Griffin Court, 15 Long Lane, London EC1A 9PN, UK. ${ }^{6}$ GlaxoSmithKline, Neurodegeneration DPU R\&D China, Neurosciences TA Unit, Clinical Unit Cambridge, Addenbrookes Hospital, Cambridge CB2 2GG, UK. ' Experimental Medicine, Neuroscience Therapeutic Area, Janssen Pharmaceutica NV, Turnhoutseweg 30, B-2340, Beerse 2340, Belgium. ${ }^{8}$ Oxford University Nuffield, Department of Clinical Neurosciences, John Radcliffe Hospital, Oxford OX3 9DU, UK. ${ }^{9}$ Department of Neurosciences, University of Messina, Via Consolare Valeria, 98125 Messina, Italy. ${ }^{10}$ National Institute of Mental Health, 6001 Executive Boulevard, BG NSC RM 7209, Rockville, MD 20892, USA.

Published: 30 Jul 2014

\section{References}

1. MCKhann GM, Knopman DS, Chertkow H, Hyman BT, Jack CR Jr, Kawas CH, Klunk WE, Koroshetz WJ, Manly JJ, Mayeux R, Mohs RC, Morris JC, Rossor MN, Scheltens P, Carrillo MC, Thies B, Weintraub S, Phelps CH: The diagnosis of dementia due to Alzheimer's disease: recommendations from the National Institute on Aging-Alzheimer's Association workgroups on diagnostic guidelines for Alzheimer's disease. Alzheimers Dement 2011 , 7:263-269.

2. Weiner MW, Veitch DP, Aisen PS, Beckett LA, Cairns NJ, Green RC, Harvey D, Jack CR, Jagust W, Liu E, Morris JC, Petersen RC, Saykin AJ, Schmidt ME, Shaw L, Shen L, Siuciak JA, Soares H, Toga AW, Trojanowski JQ, Alzheimer's Disease Neuroimaging Initiative: The Alzheimer's Disease Neuroimaging
Initiative: a review of papers published since its inception. Alzheimers Dement 2013, 9:e111-e194.

3. Innovative Medicines Initiative homepage. [www.imi.europa.eu/content/ pharma-cog]

4. Moulder KL, Snider BJ, Mills SL, Buckles VD, Santacruz AM, Bateman RJ, Morris JC: Dominantly Inherited Alzheimer Network: facilitating research and clinical trials. Alzheimers Res Ther 2013, 5:48

5. Frisoni GB, Bocchetta M, Chételat G, Rabinovici GD, de Leon MJ, Kaye J, Reiman EM, Scheltens P, Barkhof F, Black SE, Brooks DJ, Carrillo MC, Fox NC, Herholz K, Nordberg A, Jack CR Jr, Jagust WJ, Johnson KA, Rowe CC, Sperling RA, Thies W, Wahlund LO, Weiner MW, Pasqualetti P, Decarli C, ISTAART's Neurolmaging Professional Interest Area: Imaging markers for Alzheimer disease: which vs how. Neurology 2013, 81:487-500.

6. Frisoni GB, Fox NC, Jack CR Jr, Scheltens P, Thompson PM: The clinical use of structural MRI in Alzheimer disease. Nat Rev Neurol 2010, 6:67-77.

7. Damoiseaux JS, Prater KE, Miller BL, Greicius MD: Functional connectivity tracks clinical deterioration in Alzheimer's disease. Neurobiol Aging 2012, 33:e19-30.

8. Ashford JW, Salehi A, Furst A, Bayley P, Frisoni GB, Jack CR Jr, Sabri O, Adamson MM, Coburn KL, Olichney J, Schuff N, Spielman D, Edland SD, Black S, Rosen A, Kennedy D, Weiner M, Perry G: Imaging the Alzheimer brain. J Alzheimers Dis 2011, 26(Suppl 3):1-27.

9. Johnson KA, Fox NC, Sperling RA, Klunk WE: Brain imaging in Alzheimer disease. Cold Spring Harb Perspect Med 2012, 2:a006213.

10. Foster NL, Heidebrink JL, Clark CM, Jagust WJ, Arnold SE, Barbas NR, DeCarli CS, Turner RS, Koeppe RA, Higdon R, Minoshima S: FDG-PET improves accuracy in distinguishing frontotemporal dementia and Alzheimer's disease. Brain 2007, 130:2616-2635.

11. Reiman EM, Alzheimer's Disease Biomarkers Working Group for the Alliance for Aging R: Fluorodeoxyglucose positron emission tomography: emerging roles in the evaluation of putative Alzheimer's diseasemodifying treatments. Neurobiol Aging 2011, 32(Suppl 1):S44-S47.

12. Yamane $T$, Ikari $Y$, Nishio $T$, Ishii $K$, Ishii $K$, Kato $T$, Ito $K$, Silverman DH, Senda M, Asada T, Arai H, Sugishita M, Iwatsubo T, J-ADNI Study Group: Visual-statistical interpretation of 18 F-FDG-PET images for characteristic Alzheimer patterns in a multicenter study: inter-rater concordance and relationship to automated quantitative evaluation. AJNR Am J Neuroradiol 2014, 35:244-249.

13. Duara R, Gross-Glenn K, Barker WW, Chang JY, Apicella A, Loewenstein $D$, Boothe $T$ : Behavioral activation and the variability of cerebral glucose metabolic measurements. J Cereb Blood Flow Metab 1987, 7:266-271.

14. Shipley SM, Frederick MC, Filley CM, Kluger BM: Potential for misdiagnosis in community-acquired PET scans for dementia. Neurol Clin Pract 2013, 3:305-312.

15. Ostrowitzki S, Deptula D, Thurfjell L, Barkhof F, Bohrmann B, Brooks DJ, Klunk WE, Ashford E, Yoo K, Xu ZX, Loetscher H, Santarelli L: Mechanism of amyloid removal in patients with Alzheimer disease treated with gantenerumab. Arch Neurol 2012, 69:198-207.

16. Clark CM, Pontecorvo MJ, Beach TG, Bedell BJ, Coleman RE, Doraiswamy PM, Fleisher AS, Reiman EM, Sabbagh MN, Sadowsky CH, Schneider JA, Arora A, Carpenter AP, Flitter ML, Joshi AD, Krautkramer MJ, Lu M, Mintun MA, Skovronsky DM, AV-45-A16 Study Group: Cerebral PET with florbetapir compared with neuropathology at autopsy for detection of neuritic amyloid-beta plaques: a prospective cohort study. Lancet Neurol 2012, 11:669-678.

17. Frisoni GB, Jack CR: Harmonization of magnetic resonance-based manual hippocampal segmentation: a mandatory step for wide clinical use. Alzheimers Dement 2011, 7:171-174.

18. McEvoy LK, Brewer JB: Quantitative structural MRI for early detection of Alzheimer's disease. Expert Rev Neurother 2010, 10:1675-1688.

19. Sperling R, Salloway S, Brooks DJ, Tampieri D, Barakos J, Fox NC, Raskind M, Sabbagh M, Honig LS, Porsteinsson AP, Lieberburg I, Arrighi HM, Morris KA, Lu Y, Liu E, Gregg KM, Brashear HR, Kinney GG, Black R, Grundman M: Amyloid-related imaging abnormalities in patients with Alzheimer's disease treated with bapineuzumab: a retrospective analysis. Lancet Neurol 2012, 11:241-249.

20. Binnewijzend MA, Kuijer JP, Benedictus MR, van der Flier WM, Wink AM, Wattjes MP, van Berckel BN, Scheltens P, Barkhof F: Cerebral blood flow measured with 3D pseudocontinuous arterial spin-labeling MR imaging in Alzheimer disease and mild cognitive impairment: a marker for disease severity. Radiology 2013, 267:221-230. 
21. Gold BT, Jiang Y, Powell DK, Smith CD: Multimodal imaging evidence for axonal and myelin deterioration in amnestic mild cognitive impairment. J Alzheimers Dis 2012, 31(Suppl 3):S19-S31.

22. Müller HP, Grön G, Sprengelmeyer R, Kassubek J, Ludolph AC, Hobbs N, Cole J, Roos RA, Duerr A, Tabrizi SJ, Landwehrmeyer GB, Süssmuth SD: Evaluating multicenter DTI data in Huntington's disease on site specific effects: an ex post facto approach. Neurolmage Clinical 2013, 2:161-167.

23. Dyrba M, Ewers M, Wegrzyn M, Kilimann I, Plant C, Oswald A, Meindl T, Pievani M, Bokde AL, Fellgiebel A, Filippi M, Hampel H, Klöppel S, Hauenstein K, Kirste T, Teipel SJ, EDSD study group: Robust automated detection of microstructural white matter degeneration in Alzheimer's disease using machine learning classification of multicenter DTI data. PLoS One 2013, 8:e64925.

24. Filippini N, Maclntosh BJ, Hough MG, Goodwin GM, Frisoni GB, Smith SM, Matthews PM, Beckmann CF, Mackay CE: Distinct patterns of brain activity in young carriers of the APOE-epsilon4 allele. Proc Natl Acad Sci U S A 2009, 106:7209-7214.

25. Li W, Antuono PG, Xie C, Chen G, Jones JL, Ward BD, Franczak MB, Goveas JS, Li SJ: Changes in regional cerebral blood flow and functional connectivity in the cholinergic pathway associated with cognitive performance in subjects with mild Alzheimer's disease after 12-week donepezil treatment. Neuroimage 2012, 60:1083-1091.

26. Chhatwal JP, Schultz AP, Johnson K, Benzinger TL, Jack C Jr, Ances BM, Sullivan CA, Salloway SP, Ringman JM, Koeppe RA, Marcus DS, Thompson P, Saykin AJ, Correia S, Schofield PR, Rowe CC, Fox NC, Brickman AM, Mayeux R, McDade E, Bateman R, Fagan AM, Goate AM, Xiong C, Buckles VD, Morris JC, Sperling RA: Impaired default network functional connectivity in autosomal dominant Alzheimer disease. Neurology 2013, 81:736-744.

27. Fleisher AS, Sherzai A, Taylor C, Langbaum JB, Chen K, Buxton RB: Resting-state BOLD networks versus task-associated functional MRI for distinguishing Alzheimer's disease risk groups. Neuroimage 2009, 47:1678-1690.

28. Wolk DA, Detre JA: Arterial spin labeling MRI: an emerging biomarker for Alzheimer's disease and other neurodegenerative conditions. Curr Opin Neurol 2012, 25:421-428.

29. Filippi M, Agosta F: Structural and functional network connectivity breakdown in Alzheimer's disease studied with magnetic resonance imaging techniques. J Alzheimers Dis 2011, 24:455-474.

30. Sperling RA, Bates JF, Chua EF, Cocchiarella AJ, Rentz DM, Rosen BR, Schacter DL, Albert MS: fMRI studies of associative encoding in young and elderly controls and mild Alzheimer's disease. J Neurol Neurosurg Psychiatry 2003, 74:44-50.

31. Solé-Padullés $C$, Bartrés-Faz D, Junqué $C$, Vendrell $P$, Rami $L$, Clemente IC, Bosch B, Villar A, Bargalló N, Jurado MA, Barrios M, Molinuevo JL: Brain structure and function related to cognitive reserve variables in normal aging, mild cognitive impairment and Alzheimer's disease. Neurobiol Aging 2009, 30:1114-1124.

32. Celone KA, Calhoun VD, Dickerson BC, Atri A, Chua EF, Miller SL, DePeau K, Rentz DM, Selkoe DJ, Blacker D, Albert MS, Sperling RA: Alterations in memory networks in mild cognitive impairment and Alzheimer's disease: an independent component analysis. J Neurosci 2006, 26:10222-10231.

33. Atri A, O'Brien JL, Sreenivasan A, Rastegar S, Salisbury S, DeLuca AN, O'Keefe KM, LaViolette PS, Rentz DM, Locascio JJ, Sperling RA: Test-retest reliability of memory task functional magnetic resonance imaging in Alzheimer disease clinical trials. Arch Neurol 2011, 68:599-606.

34. Raichle ME, MacLeod AM, Snyder AZ, Powers WJ, Gusnard DA, Shulman GL: A default mode of brain function. Proc Natl Acad Sci U S A 2001, 98:676-682.

35. Mintun MA, Larossa GN, Sheline YI, Dence CS, Lee SY, Mach RH, Klunk WE, Mathis CA, DeKosky ST, Morris JC: [11C]PIB in a nondemented population: potential antecedent marker of Alzheimer disease. Neurology 2006, 67:446-452.

36. Dukart J, Kherif F, Mueller K, Adaszewski S, Schroeter ML, Frackowiak RS, Draganski B, Alzheimer's Disease Neuroimaging I: Generative FDG-PET and MRI model of aging and disease progression in Alzheimer's disease. PLOS Comput Biol 2013, 9:e1002987.

37. Zeng F, Goodman MM: Fluorine-18 radiolabeled heterocycles as PET tracers for imaging beta-amyloid plaques in Alzheimer's disease. Curr Top Med Chem 2013, 13:909-919.
38. Wood H: Alzheimer disease: [C]PBB3 - a new PET ligand that identifies tau pathology in the brains of patients with AD. Nat Rev Neurol 2013, 9:599.

39. Chien DT, Bahri S, Szardenings AK, Walsh JC, Mu F, Su MY, Shankle WR Elizarov A, Kolb HC: Early clinical PET imaging results with the novel PHF-tau radioligand [F-18]-T807. J Alzheimers Dis 2013, 34:457-468.

40. Fagan AM, Roe CM, Xiong C, Mintun MA, Morris JC, Holtzman DM: Cerebrospinal fluid tau/beta-amyloid(42) ratio as a prediction of cognitive decline in nondemented older adults. Arch Neurol 2007, 64:343-349.

41. Salloway S, Sperling R, Fox NC, Blennow K, Klunk W, Raskind M, Sabbagh M, Honig LS, Porsteinsson AP, Ferris S, Reichert M, Ketter N, Nejadnik B, Guenzler V, Miloslavsky M, Wang D, Lu Y, Lull J, Tudor IC, Liu E, Grundman M, Yuen E, Black R, Brashear HR, Bapineuzumab 301 and 302 Clinical Trial Investigators: Two phase 3 trials of bapineuzumab in mild-to-moderate Alzheimer's disease. N Engl J Med 2014, 370:322-333.

42. Jack CR Jr, Dickson DW, Parisi JE, Xu YC, Cha RH, O'Brien PC, Edland SD, Smith GE, Boeve BF, Tangalos EG, Kokmen E, Petersen RC: Antemortem MRI findings correlate with hippocampal neuropathology in typical aging and dementia. Neurology 2002, 58:750-757.

43. Gilman S, Koller M, Black RS, Jenkins L, Griffith SG, Fox NC, Eisner L, Kirby L, Rovira MB, Forette F, Orgogozo JM, AN1792(QS-21)-201 Study Team: Clinical effects of Abeta immunization (AN1792) in patients with AD in an interrupted trial. Neurology 2005, 64:1553-1562.

44. Boccardi M, Bocchetta M, Ganzola R, Robitaille N, Redolfi A, Duchesne S, Jack CR Jr, Frisoni GB: EADC-ADNI Working Group on The Harmonized Protocol for Hippocampal Volumetry and for the Alzheimer's Disease Neuroimaging Initiative: Operationalizing protocol differences for EADC-ADNI manual hippocampal segmentation. Alzheimers Dement 2013, May 21. doi: 10.1016/j.jalz.2013.03.0013

45. Holland D, McEvoy LK, Dale AM, Alzheimer's Disease Neuroimaging Initiative: Unbiased comparison of sample size estimates from longitudinal structural measures in ADNI. Hum Brain Mapp 2012, 33:2586-2602.

46. Barkhof F, Daams M, Scheltens P, Brashear HR, Arrighi HM, Bechten A, Morris K, McGovern M, Wattjes MP: An MRI rating scale for amyloid-related imaging abnormalities with edema or effusion. AJNR Am J Neuroradiol 2013, 34:1550-1555.

47. Moseley M: Diffusion tensor imaging and aging - a review. NMR Biomed 2002, 15:553-560.

48. Johnson SC, Schmitz TW, Moritz CH, Meyerand ME, Rowley HA, Alexander AL, Hansen KW, Gleason CE, Carlsson CM, Ries ML, Asthana S, Chen K, Reiman EM, Alexander GE: Activation of brain regions vulnerable to Alzheimer's disease: the effect of mild cognitive impairment. Neurobiol Aging 2006, 27:1604-1612.

49. Lorenzi M, Beltramello A, Mercuri NB, Canu E, Zoccatelli G, Pizzini FB, Alessandrini F, Cotelli M, Rosini S, Costardi D, Caltagirone C, Frisoni GB: Effect of memantine on resting state default mode network activity in Alzheimer's disease. Drugs Aging 2011, 28:205-217.

50. Hu WT, Wang Z, Lee VM, Trojanowski JQ, Detre JA, Grossman M: Distinct cerebral perfusion patterns in FTLD and AD. Neurology 2010, 75:881-888.

\subsection{6/alzrt276}

Cite this article as: Merlo Pich et al:: Imaging as a biomarker in drug discovery for Alzheimer's disease: is MRI a suitable technology? Alzheimer's Research \& Therapy 2014, 6:51 